\title{
LA APLICACIÓN DEL DERECHO INTERNACIONAL GENERAL A LAS ACTUACIONES DE LAS ORGANIZACIONES INTERNACIONALES. LA PRÁCTICA DE LAS COMUNIDADES EUROPEAS-UNIÓN EUROPEA
}

\author{
José Manuel SÁNCHEZ PATRÓN*
}

RESUMEN: El presente trabajo de investigación muestra como las organizaciones internacionales contribuyen a la formación y a la aplicación del derecho internacional general - la costumbre y los principios generales del derecho internacional-, pese a que no constituye una fuente formal de su derecho institucional. Asimismo, el derecho internacional general es utilizado para fundamentar y limitar las actuaciones de las organizaciones internacionales en la práctica, tal y como ha podido confirmarse por el estudio de la jurisprudencia del Tribunal de Justicia de las Comunidades Europeas-Unión Europea en relación con esta organización internacional de integración.

ABSTRACT: This work of research shows that International organisations contributed to the origin and the application of the International general law-custom law and general principles of International law-, although it is not a formal source of its Institutional law. Also, International general law is used to found and to limit the practice of the International organisation, as we were able to confirm trough the analysis of the case law of The Court of Justice of European Community-European Community in relation with this International organisation of integration.

RÉSUMÉ: Ce travail de recherche expose que les Organisations internationales ont fait une contribution a la formation et l'application du Droit international général - coutume et principes général du Droit international-, tandis ce n'est pas une source formel de son Droit institutionnel. Surplus, le Droit international général est utilisé pour établir et limiter les actuations du les Organisations internationales dans la practice, comme le analyse de la jurisprudence de la Cour de Justice de les Communautés européennes a confirmé pour rapport au cette Organisation international d'intégration.

* Profesor del Departamento de Derecho Internacional "Adolfo Miaja de la Muela" de la Universidad de Valencia (España). 
SUMARIO: I. Introducción. II. La fundamentación de las actuaciones de la Unión Europea sobre la base del derecho internacional general. III. La limitación de las actuaciones de la Unión Europea sobre la base del derecho internacional general.

IV. Conclusión.

\section{INTRODUCCIÓN}

El Tribunal Internacional de Justicia declaró en su opinión consultiva de 20 de diciembre de 1980, que: "(1)a organización internacional es un sujeto de derecho internacional ligado en tanto que tal por todas las obligaciones que le imponen las reglas generales del derecho internacional, su acto constitutivo o los acuerdos internacionales de los que son parte". ${ }^{1}$

Esto quiere decir que el ordenamiento jurídico de una organización internacional lo constituye el conjunto de reglas derivadas de la voluntad explícita (competencias expresamente recogidas en el tratado constitutivo) e implícita (competencias tácitamente reconocidas en su tratado constitutivo) de sus Estados miembros. Además, las reglas anteriores se suman a las que proceden de la voluntad de la propia organización internacional que permite conformar su particular práctica convencional y consuetudinaria. A través de la voluntad de la propia organización internacional, ésta puede, de forma explícita, suscribir tratados internacionales con terceros o bien, de modo implícito, contribuir a la formación y aplicación de la costumbre internacional.

Sin embargo, la opinión consultiva del Tribunal Internacional de Justicia añade que las organizaciones internacionales son un sujeto de derecho internacional que se encuentra vinculado por "reglas generales del derecho internacional" que - como es el caso de la costumbre o los principios generales del derecho internacional - forman parte de su ordenamiento jurídico. ${ }^{2}$ Así pues, las organizaciones internacionales se encuentren ligadas a las "reglas generales del derecho internacional", lo que evoca la idea de que sus actuaciones concretas han de respetar tales "re-

1 TIJ. Opinión consultiva relativa a la interpretación del acuerdo OMS-Egipto de 20 de diciembre de 1980, Rec. 1980, párr. 37.

2 Los principios generales del derecho internacional son: "la formulación generalizada de las principales reglas del derecho internacional derivadas del derecho consuetudinario o del derecho convencional". Salmon, J. (dir), Dictionnaire de Droit International Public, Bruselas, Bruylant, 2001, pp. 880 y 881 . 
glas generales". Sin embargo, cabe preguntarse, igualmente, si también permitiría fundamentarlas.

Recientes estudios doctrinales se han ocupado de la contribución de las organizaciones internacionales a la formación y aplicación de la costumbre internacional; ${ }^{3}$ pero sólo algunos de ellos han centrado su atención en el examen específico de la función que las normas internacionales de carácter consuetudinario pueden desempeñar como instrumento jurídico que permite fundamentar y limitar la actuación de tales organizaciones internacionales en el marco de sus respectivas competencias. ${ }^{4}$

Precisamente, el presente trabajo pretende examinar como la costumbre y los principios generales del derecho internacional son utilizados como base y límite de las actuaciones institucionales. Para llevar a cabo nuestro propósito, fijaremos nuestra atención en la práctica de la Unión Europea-Comunidades Europeas (en adelante UE), más concretamente, a través del estudio de la jurisprudencia de su Tribunal de Justicia. Esta opción permitirá que los resultados obtenidos de la labor propuesta tengan una mayor virtualidad por el hecho de centrarse en una organización regional que a diferencia del resto de las organizaciones internacionales se singulariza por una mayor intensidad en la cesión y ejercicio de las competencias atribuidas por sus Estados miembros.

\section{LA FUNDAMENTACIÓN DE LAS ACTUACIONES \\ DE LA UNIÓN EUROPEA SOBRE LA BASE DEL DERECHO \\ INTERNACIONAL GENERAL}

\section{La formulación teórica}

Que la UE constituya un tipo de organización internacional caracterizado por la cesión de competencias estatales, justifica que la tipología y el ámbito de las mismas esté mucho más delimitado en este caso concreto, lo que tiene reflejo en el carácter pretendidamente taxativo y preciso

3 Especialmente, véase Cahin, G., La coutume international et les organisations internacionales, París, Pedone, 2001. También: Cardona Lloréns, J., "L'incidence des Organisations internationales sur les transformations du Droit international: réflexions au terme du XX siècle", en varios autores, Les Droits de l'homme à l'aube du XXI siècle. Karel Vasak Amicorum Liber, Bruselas, Bruylant, 1999, pp. 975-1029.

4 Por ejemplo, véase Puissochet, J. P., "La place du droit international dans la jurisprudence de la Cour de Justice des Communautés européennes", en varios autores, Scritti in onore di Giuseppe Federico Manzini, Milán, Giuffre Editore, 1998, vol. II, pp. 779 y ss. 
con el que dichas competencias estatales están formuladas en sus tratados constitutivos. Con ello se pretende impedir que la entidad supranacional pueda arrogarse el ejercicio de competencias que los Estados miembros no han procedido ha transferirle de manera efectiva, lo que explica que sus tratados constitutivos hayan evitado una referencia genérica al derecho internacional general entre sus disposiciones, soslayando así que esta mención pudiera aprovecharse para extender el ejercicio de las competencias atribuidas más allá de lo deseado por los Estados miembros. Una simple hojeada al contenido de los tratados constitutivos de la UE permite comprobar como éstos enumeran de modo más o menos exhaustivo cuales son los instrumentos jurídicos desde los que van a ejercerse las competencias que le han sido atribuidas, pero en ningún momento contempla la posibilidad de que este ejercicio pueda estar fundamentado en fuentes tales como la costumbre o los principios generales del derecho internacional. ${ }^{5} \mathrm{El}$ nuevo tratado por el que se establece una Constitución para Europa sí prevé algunas referencias puntuales al derecho internacional general en el conjunto de sus disposiciones normativas, pero estas menciones concretas están referidas a determinadas actuaciones de la UE que revisten un carácter sectorial y accesorio. ${ }^{6}$

Sin embargo y pese a lo anterior, el propio funcionamiento de la UE puso en evidencia la necesidad de recurrir a fuentes jurídicas distintas de los propios tratados constitutivos para responder correctamente a los desafíos jurídicos que le plantea la dinámica comunitaria. La falta de previsión existente en los textos convencionales y la imposibilidad de recurrir a las competencias implícitas que derivaran de los mismos, llevó a que las instituciones comunitarias recurriesen a fuentes de inspiración externas que permitiesen resolver los problemas planteados. Este proceder permitió que estas fuentes materiales externas terminaran por integrarse de facto en el sistema de fuentes de la organización regional, convirtiéndose así en una base jurídica imprevista y complementaria que permitiría fundamentar sus actuaciones. Así, la propia dinámica comunitaria ha acabado por integrar la costumbre y los principios generales del derecho

5 Véase Tratado de la Unión Europea y Tratado constitutivo de la Comunidad Europea, Diario Oficial de la Unión Europea, C325/1 de 24 de diciembre de 2002. También: art. I-33.1 del tratado por el que se establece una Constitución para Europa, Diario Oficial de la Unión Europea, C310 de 16 de diciembre de 2004. Sobre el particular: Diez-Hochleitner, J., La posición del derecho internacional en el ordenamiento comunitario, Madrid, McGrawHill, 1998, pp. 11-15.

6 Arts: I-3.4, III-292.1, 292.2b) y 321.2. 
internacional en el ordenamiento jurídico comunitario, confirmándose la opinión según la cual: "( $\mathrm{t}$ )he constitutional texts of international organizations do not exist in a vacuum, nor are the activities of their organs governed solely by those texts. These texts form only a part of international law and they operate within that broader context... there is clear evidence of an intention to promote and apply international law in general, whenever that is appropriate to their activities". ${ }^{7}$

\section{La verificación práctica}

A principios de la década de los ochenta, la práctica comunitaria relacionada con el derecho internacional general era casi inexistente. ${ }^{8}$ Sin embargo y desde esta fecha, el Tribunal de Justicia comenzó a recurrir a la costumbre y a los principios generales del derecho internacional para fundamentar jurídicamente la conformidad de las actuaciones llevadas a efecto por las instituciones comunitarias. El análisis de su jurisprudencia nos permite agrupar los pronunciamientos adoptados por la jurisdicción europea en torno a las dos finalidades distintas: una, colmar las lagunas normativas del propio ordenamiento comunitario; y otra, suplir las deficiencias existentes en el mismo. Tanto lo uno como lo otro ponen en evidencia que el derecho internacional general se encuentra integrado en la práctica comunitaria en tanto que fuente jurídica del derecho comunitario.

Con respecto a la primera de las finalidades, la empresa francesa A. Islais S. encargó a la también empresa de su misma nacionalidad E. A. Mondiet, la elaboración de doscientas redes de enmalle de deriva destinadas a la pesca del atún. Como consecuencia de la modificación de un reglamento comunitario destinado a regular el empleo de técnicas de pesca para la conservación de los recursos pesqueros, el empleo de las redes de enmalle solicitadas fueron prohibidas. Pese a ello, la empresa E. A. Mondiet solicitó el pago de la mercancía encargada, presentando una demanda de pago ante los órganos jurisdiccionales franceses. El órgano juris-

7 Bowett, D. W., "The role of international organisations in the implementation of international law", en varios autores, Le droit international à l'aube du XXI siècle. Réflexions de codificateurs, Nueva York, Naciones Unidas, 1997, p. 167.

8 Jacot-Guillarmod, Droit communautaire et Droit international public. Etudes des sources internationales de l'ordre juridique des Communautés européennes (Pescatore, P., Préf.,), Génova, Librairie de 1'Université-Georg \& Cie S. A., 1979, p. 220. 
diccional competente consideró que la modificación del reglamento comunitario podía constituir una causa de fuerza mayor que eximiese a la empresa A. Islais S. del pago de las redes de enmalle encargadas. Con esta finalidad, el órgano jurisdiccional francés elevó una cuestión prejudicial al Tribunal de Justicia en la que le formulaba una serie de preguntas, entre las que figuraba la competencia de la entonces Comunidad Económica Europea para limitar la pesca de los buques nacionales en alta mar a fin de proteger los recursos pesqueros. El Tribunal de Justicia respondió a esta consulta señalando que: "(era) jurisprudencia reiterada... que, en lo que se refiere a la alta mar, la Comunidad, tiene en las materias que entran dentro de sus atribuciones, la misma competencia normativa que el derecho internacional reconoce al Estado en el que esté registrado el buque o cuyo pabellón enarbole". 9

A mayor abundamiento:

(E)n materia de pesca, dicha competencia está prevista por la Convención de Ginebra de 29 de abril de 1958 sobre la pesca y la conservación de los recursos vivos de la alta mar... la cual codifica normas generales establecidas en esta materia por la costumbre internacional, y por la Convención de las Naciones Unidas sobre el Derecho del Mar de 10 de diciembre de 1982 ... Esta última aún no (había) entrado en vigor, pero muchas de sus disposiciones están consideradas como la expresión del estado actual del derecho marítimo consuetudinario. ${ }^{10}$

\section{Precisamente:}

(E)l artículo 6 de la mencionada Convención de Ginebra de 29 de abril de 1958 reconoce el interés de los Estados ribereños en lo que respecta a los recursos vivos en la parte de alta mar adyacente a sus aguas jurisdiccionales. Además los artículos 117 y 118 de la Convención de las Naciones Unidas sobre el Derecho del Mar obligan a todos los miembros de la Comunidad internacional a cooperar en la conservación y administración de los recursos vivos de la alta mar. ${ }^{11}$

9 TJ. Sentencia "E. A. Mondiet Sa c. A. Islais S" de 24 de noviembre de 1993, as. C-405/92, Rec. 1993, párr. 12. Originariamente, véase sentencia "Cornelis Kramer y otros" de 14 de julio de 1976, as. 3, 4 y 6-76, Rec. 1976, párr. 31.

$10 \quad$ Ibidem, párr. 13.

11 Ibidem, párr. 14. 
Por consiguiente: “(d)e lo expuesto resulta que la Comunidad es competente para adoptar, respecto a los buques que enarbolen pabellón de un Estado miembro o que estén registrados en un Estado miembro, medidas destinadas a la conservación de los recursos pesqueros en alta mar". 12

El razonamiento expuesto por el Tribunal de Justicia confirma la presunción de que la UE, como organización internacional, está sometida al derecho internacional general tal y como pueden estarlo sus respectivos Estados miembros. Así, la organización regional reivindica el ejercicio de una competencia exclusiva que tiene atribuida por sus Estados miembros en una materia determinada: la conservación de los recursos biológicos marinos en el marco de la política pesquera común. Para ello, la organización europea considera que las actuaciones desarrolladas en este ámbito material se encuentran fundamentadas en el articulado del Convenio de Ginebra de 29 de abril de 1958 y la Convención de las Naciones Unidas sobre Derecho del Mar de 10 de diciembre de 1982. Aunque ésta última no entró en vigor hasta el 16 de noviembre de 1994, el Tribunal de Justicia invocó el artículo 6 del Convenio de Ginebra de 29 de abril de 1958 , que si se encontraba en vigor y por la que no se encontraba vinculado como parte. Esta circunstancia permite preguntarnos como es posible que la Comunidad Económica Europea fundamente sus actuaciones con arreglo a una regla internacional por la que no está vinculada jurídicamente por el simple hecho de que no ha prestado su consentimiento a la misma; lo que sí sucede con sus Estados miembros. Aquí podría aplicarse analógicamente la tesis de la sucesión estatal y el principio de continuidad de las obligaciones internacionales, que permitiría que la organización europea se subrogase en los derechos y obligaciones asumidos por los Estados miembros con anterioridad. Sin embargo, el propio Tribunal de Justicia se encargó de rechazar esta doctrina desde los inicios de su jurisprudencia, señalando que: "(e)n la medida en la que en virtud del tratado CEE, la Comunidad ha asumido competencias anteriormente ejercidas por los Estados miembros en el dominio de la aplicación de (un tratado internacional), las disposiciones de este (tratado internacional) no tienen por efecto vincular a la Comunidad". ${ }^{13}$

12 Ibidem, párr. 15.

13 TJ. Sentencia "International Fruit Company NV y otros" de 12 de diciembre de 1972, as. 21-24/72, Rec. 1972, párr. 18. 
Muy al contrario y en este mismo asunto, el Tribunal de Justicia deja entrever que para que una norma jurídica internacional vincule de algún modo a la organización regional es necesario que ésta se encuentre vinculada por la disposición normativa en particular. ${ }^{14}$ Este punto de partida nos obliga a buscar una explicación jurídica diferente a la posibilidad de que la rebautizada Comunidad Económica Europea pudiera fundamentar el ejercicio de sus competencias en normas internacionales a las que éstos no han prestado su consentimiento, aunque sí lo hubiesen hecho los Estados miembros encargados de atribuirle tales competencias. La única justificación jurídica posible se encuentra en la naturaleza consuetudinaria de las disposiciones normativas de los tratados internacionales sobre derecho del mar a los que la sentencia del Tribunal de Justicia se ha referido en sus fundamentos jurídicos. En efecto, las disposiciones mencionadas forman parte del derecho internacional general y como tales vinculan a la Comunidad Económica Europea en tanto que organización internacional. Concretamente, el Tribunal de Justicia se esfuerza por subrayar el carácter consuetudinario de dichas normas jurídicas cuando subraya que son la "expresión del estado actual del derecho marítimo consuetudinario". Con ello consigue demostrar que la Comunidad Económica Europea se encuentra vinculada por tales disposiciones normativas en tanto que costumbre internacional, lo que le permite fundamentar la adopción de actos normativos acerca de una materia cuya gestión tiene atribuida sobre la base del derecho internacional general. ${ }^{15}$ Así, la costumbre y los principios generales del derecho internacional se convierten en fuente jurídica de la organización internacional, ${ }^{16}$ y por ende, de su ordenamiento jurídico.

14 En palabras del profesor David “(1)e droit international aplicable à l'organisation internationale ne comprend donc pas, par une sorte de cumul extensif, toutes les régles internationales particulières liant les différents Etats membres de 1'organisation internationale: la personnalité juridique de l'organisation internationale, distincte de celles des Etats membres, ainsi que la relativité du droit international s'opposent à un tel résultat". David, E., "Le droit international applicable aux organisations internationales", en varios autores, Mélanges en Hommage à Michael Waelbroeck, Bruselas, Bruylant, vol. I, 1999, p. 19.

15 El TJ volvió a reiterar con posterioridad que: "es jurisprudencia reiterada que, en lo que se refiere al alta mar, la Comunidad tiene, en las materias comprendidas dentro de sus atribuciones, la misma competencia normativa que el derecho internacional reconoce al Estado en el que está registrado el buque o cuyo pabellón enarbole". Véase sentencia "Comisión c. Consejo" de 19 de marzo de 1996, as. C-25/94, Rec. 1996, párr. 44.

16 Véase David. E., "La porte juridique des actes institutionnels", Thesaurus Acrosium, vol. XIX, 1992, pp. 241-245. 
También relacionado con el derecho internacional del mar, un trabajador alemán ejerció su trabajo en buques o instalaciones ubicadas en la plataforma continental de los Países Bajos y denunció la resolución de su contrato de trabajo por parte de una empresa escocesa que lo tenía contratado como cocinero. Para resolver el litigio planteado, el Tribunal de Justicia tuvo que pronunciarse acerca de la cuestión de si una actividad ejercida en la plataforma continental de los Países Bajos podía considerarse como una actividad desarrollada en el territorio del Estado holandés, lo que permitiría aplicarle el Convenio de Bruselas de 27 de septiembre de 1968 sobre la competencia judicial y la ejecución de resoluciones judiciales en materia civil y mercantil. Según el Tribunal de Justicia: "(a) falta de disposición de dicho Convenio que regule este aspecto de su ámbito de aplicación y falta de otros indicios sobre la respuesta que deba darse a esta cuestión, procede remitirse a los principios del derecho internacional público relativos al régimen jurídico de la plataforma continental y, en particular, a la Convención de Ginebra, que era aplicable a los Países Bajos en el momento en el que se produjeron los hechos del asunto principal". ${ }^{17}$

A partir de aquí, el Tribunal de Justicia examinó el articulado del Convenio de Ginebra de 29 de abril de 1958 e invocó una sentencia del Tribunal Internacional de Justicia, en la que afirmaba que: "los derechos del Estado ribereño sobre la zona de la plataforma continental... constituye una prolongación natural de su territorio terrestre bajo el mar que existen ipso facto y ab initio en virtud de la soberanía del Estado sobre este territorio y como extensión de ésta, bajo la forma del ejercicio de derechos de soberanía para explorar el lecho marino y explotar sus recursos naturales". 18

De ello, el Tribunal de Justicia deduce que el trabajo realizado por cuenta ajena en la plataforma continental de los Países Bajos puede considerarse como una actividad laboral desarrollada en el territorio de dicho Estado. Esta conclusión permite que el Convenio de Bruselas de 27 de septiembre de 1968 sobre la competencia judicial y la ejecución de resoluciones judiciales en materia civil y mercantil, pueda ser aplicado al

17 TJ. Sentencia "Herbert Weber y Universal Orden Services Ltd" de 27 de febrero de 2002, as. C-37/00, Rec. 2002, párr. 31.

18 Ibidem, párr. 34. El Tribunal de Justicia cita el párrafo 19 de la sentencia del Tribunal Internacional de Justicia sobre los asuntos de la plataforma continental del Mar del Norte de 20 de febrero de 1969 (Rec. 1969, p. 3). 
caso. A falta de una disposición especifica que permita resolver la cuestión planteada, el Tribunal de Justicia acude al derecho internacional general para completar una laguna existente en un convenio del que ostenta la competencia última para interpretar y aplicar.

Pero el recurso a la costumbre y los principios generales del derecho internacional no sirven únicamente para colmar las lagunas jurídicas presentes en el ordenamiento jurídico comunitario sino que también permite suplir las deficiencias del mismo, completando así la base jurídica sobre la que se asienta las actuaciones comunitarias.

Sobre el particular, la jurisprudencia del Tribunal de Justicia es especialmente rica en materia de derecho de los tratados internacionales. La normativa jurídica que regula el régimen de los tratados internacionales es frecuentemente invocada por el Tribunal de Justicia para solucionar los litigios en los que la solución de los mismos depende de las normas establecidas por el derecho internacional general relativo a esta materia.

Así, un importador de vinos alemán fue obligado a pagar un impuesto especial — previsto por la legislación germánica — por la introducción de vino portugués en su país. Para el importador de vinos alemán, la obligación de pagar este impuesto especial contradecía un acuerdo jurídico celebrado entre la Comunidad Económica Europea y Portugal de fecha 22 de julio de 1972. Según este convenio internacional, las partes contratantes se obligaban a no imponer cualquier medida o práctica de naturaleza fiscal interna que pudiera discriminar los productos procedentes de ambas partes contratantes. Pues bien, una de las cuestiones que se le planteó al Tribunal de Justicia es si el acuerdo internacional referido era directamente aplicable a las partes contratantes hasta el punto de que los operadores económicos pudieran invocar los derechos reconocidos en el mismo. El Tribunal de Justicia respondió señalando que:

Además:

(S)egún las reglas generales del derecho internacional, todo acuerdo debe ser ejecutado de buena fe por las partes. Si cada parte contratante es responsable completa de los compromisos que ella ha suscrito, le pertenece, en cambio, determinar los medios de derecho propios a cumplir con este fin en su orden jurídico, a menos que el acuerdo, interpretado a la luz de su objeto y de su finalidad, no determine, éste mismo, dichos medios. ${ }^{19}$ 
A la vista de ello y tras examinar sus disposiciones, el Tribunal de Justicia llegó a la conclusión de que el acuerdo internacional en cuestión es directamente aplicable y que podía ser invocado por los operadores económicos interesados. Esto llevó a que el impuesto especial que pretendía exigirse a las importaciones de vino portugués no pudiese ser aplicado como consecuencia de la predominancia de las disposiciones del convenio internacional sobre la legislación interna. De este modo, el Tribunal de Justicia se sirve del derecho internacional general en materia de tratados para interpretar el articulado del acuerdo bilateral celebrado entre la Comunidad Económica Europea y Portugal. Esta remisión le ha permitido completar los preceptos del acuerdo internacional en cuestión, ayudando a determinar cual era su alcance y sus efectos para las partes que lo suscribieron.

La desaparecida República Socialista de Checoslovaquia celebró un tratado bilateral con la República de Austria en virtud del cual la utilización de la denominación "Bud" en el Estado austriaco está reservada a la cerveza producida en la República Socialista de Checoslovaquia. Sin embargo, una empresa austriaca comenzó a comercializar en el país austriaco la cerveza estadounidense "American Bud". A juicio de una productora checa, la utilización de esta denominación, reservada a la cerveza producida en la República Socialista de Checoslovaquia, incumplía el acuerdo internacional suscrito en su momento. Sin embargo, dicho tratado bilateral se celebró antes de que la República Federativa de Checoslovaquia se disolviese en dos Estados soberanos nuevos (República Checa y República Eslovaca) y que la República de Austria ingresase en las Comunidades Europeas como nuevo Estado miembro, lo que se produjo el 1 de enero de 1993 y el 1 de enero de 1995, respectivamente. Ambas circunstancias llevaron a que el Tribunal de Justicia dilucidase si el tratado internacional invocado continuaba en vigor. Para el órgano judicial

(C)onsta en autos que, en la fecha del referido desmembramiento, existía una práctica internacional ampliamente reconocida basada en el principio de la continuidad de los tratados. Con arreglo a dicha práctica, cuando uno de los Estados Parte en un tratado bilateral no ha manifestado su voluntad de renegociarlo o de denunciarlo, se considera, en principio, que dicho tratado sigue en vigor con respecto a los Estados que suceden al Estado que ha sufrido el desmembramiento. Parece, en efecto, que el principio de continuidad de los tratados, entendido de este modo, constituye, al menos en lo que atañe al caso específico de un desmembramiento completo de Esta- 
dos y sin perjuicio de la posibilidad de denuncia o renegociación de los tratados, un principio de referencia reconocido ampliamente en la fecha del desmembramiento de que se trata. En cualquier caso, y sin que sea necesario que el Tribunal de Justicia se pronuncie sobre la cuestión de si en la fecha del desmembramiento de la República Federativa de Checoslovaquia el referido principio de la continuidad de los tratados constituía una norma consuetudinaria de derecho internacional, es indiscutible que la aplicación de dicho principio en la práctica internacional del derecho sobre los tratados era en aquella fecha plenamente conforme al derecho internacional. ${ }^{20}$

En aplicación de lo dicho, el Tribunal de Justicia pasó a comprobar cual había sido la voluntad de los Estados implicados, advirtiendo que el derecho interno de la República Checa apostaba por el principio de continuidad automática en materia de tratados, mientras que la República de Austria, propugnaba el de extinción automática en materia de tratados o también denominado principio de tabula rasa. No obstante, la jurisdicción europea tuvo indicios de que algunos tratados internacionales se exceptuaban a esta última regla de extinción automática, y entre éstos se encontraba el convenio bilateral en cuestión. Por tal motivo, el Tribunal de Justicia encomendó al órgano judicial remitente del recurso prejudicial que comprobase cual era la situación jurídica exacta del susodicho acuerdo internacional, avanzando que, en caso de que pudiera confirmarse la continuidad de su vigencia, dicho convenio bilateral debería seguir cumpliéndose "en virtud del derecho internacional". ${ }^{21}$

Así las cosas, la normativa comunitaria que pudiera serle de aplicación a la República de Austria tras su ingreso en las Comunidades Europeas, debía compatibilizarse en la medida de lo posible con los compromisos internacionales existentes con anterioridad a dicha admisión en la condición de nuevo Estado miembro. Para ello, el Tribunal de Justicia acude a la costumbre y a los principios generales del derecho internacional para determinar si aquel compromiso internacional continuaba vigente o bien había sido extinguido. Este recurso al derecho internacional general muestra como este tipo de reglas jurídicas internacionales completan las insuficiencias de las que adolece el ordenamiento jurídico co-

20 TJ. Sentencia "Budejovicky Budvar, narodni podnik y Rudolf Ammersin GMBH" de 18 de novimebre de 2003, as. C-216/01, Rec. 2003, párrs. 152-154.

21 Ibidem, párr. 173. 
munitario, a fin de resolver satisfactoriamente un buen número de cuestiones y litigios que se presentan ante el Tribunal de Primera Instancia o el propio Tribunal de Justicia.

\section{LA LIMITACIÓN DE LAS ACTUACIONES DE LA UNIÓN EUROPEA SOBRE LA BASE DEL DERECHO INTERNACIONAL GENERAL}

\section{La formulación teórica}

El hecho de que las organizaciones internacionales estén sometidas al derecho internacional general tiene la contrapartida de que la costumbre y los principios generales del derecho internacional no sólo van a ser utilizados para fundamentar de forma autónoma o complementaria las actividades de las organizaciones internacionales, sino que también constituyen una limitación a las mismas. Esto quiere decir que, pese a que una organización internacional no disponga de competencias en materia de derechos humanos, esta falta de atribución competencial no le faculta para ignorar o menoscabar tales derechos básicos en sus actuaciones. Al contrario, las organizaciones internacionales, como cualquier otro sujeto de derecho internacional, se encuentran vinculadas por el derecho internacional general, que contempla el respeto necesario de los derechos humanos entre sus reglas y principios. Esta circunstancia obliga a que cualquier organización internacional $-\mathrm{y}$ por extensión todos los sujetos de derecho internacional - respete aquellos derechos elementales en el ejercicio de sus competencias respectivas.

Aunque la práctica desplegada por las instituciones comunitarias demuestra que sus actividades están limitadas por la costumbre y los principios generales del derecho internacional, lo cierto es que su Tribunal de Justicia no ha declarado esta sujeción de las actuaciones de la UE al derecho internacional general hasta fechas recientes. Concretamente, el Tribunal de Justicia señaló en su sentencia de 16 de junio de 1998 que: "(1)as competencias de la comunidad deben ejercerse respetando el derecho internacional... la Comunidad está obligada a respetar las normas del derecho consuetudinario internacional al adoptar un Reglamento". 22

22 TJ. Sentencia "Racke GMBH \&Co. y Hauptzollamt Mainz" de 16 de junio de 1998, C-162/96, Rec. 1998, párr. 45. 
Ya que: "las normas del derecho consuetudinario internacional... vinculan a las instituciones de la comunidad y forman parte del ordenamiento jurídico comunitario". ${ }^{23}$

A partir de este precedente jurisprudencial, el Tribunal de Justicia no sólo establece la sumisión de la actividad comunitaria al derecho internacional general sino que llega a invalidar un acto normativo de la organización internacional basándose en la costumbre internacional. Esto significa que el derecho internacional general queda integrado en el ordenamiento jurídico comunitario con un rango superior al del conjunto de actos normativos de derecho derivado. Aunque la sentencia referida no es muy explícita sobre el particular, el hecho de que acabe anulando un reglamento comunitario por ser contrario a la costumbre internacional es suficiente para llegar a la conclusión de que el derecho internacional general posee rango superior al resto de los actos normativos adoptados por las instituciones comunitarias, a excepción de los tratados internacionales celebrados con terceros. ${ }^{24}$ La única duda que se plantea está referida a la solución jurídica que debería otorgarse a una eventual contradicción entre costumbre y principios generales del derecho internacional y el propio derecho originario de la Unión Europea. No obstante, pese a que este problema no se ha planteado en la práctica, una hipotética colisión entre el derecho internacional general y los tratados constitutivos de la UE, parece que debe resolverse a favor de éste último, ${ }^{25}$ siempre y cuando no nos olvidemos que las normas internacionales de ius cogens deberán ser observadas indefectiblemente. ${ }^{26}$

Por último, una prueba adicional que demuestra la incorporación de la costumbre y los principios generales del derecho internacional a las fuentes jurídicas de esta organización regional — que se suma a la ya apuntada sobre la oportunidad de invalidar los actos normativos adoptados por las instituciones comunitarias - es la posibilidad de que los propios particulares impugnen un acto comunitario sobre la base del derecho

23 Ibidem, párr. 46.

24 Véase Isaac, G., Manual de derecho comunitario general, 5a ed., Barcelona, Ariel, 2000, p. 213.

25 Véase Roldán Barbero, J., "La costumbre internacional, la claúsula rebus sic stantibus y el derecho comunitario (A propósito de la sentencia Racke dictada por el TJCE el 16 de junio de 1998)", Revista Española de Derecho Internacional, vol. L, núm. 2, julio-diciembre de 1998, pp. 27 y 28

$26 \mathrm{Al}$ respecto, véase los siguiente artículos del tratado por el que se establece una Constitución para Europa, ibidem: I-3.4, III-292.1, III-292.2b), III-321.2. 
internacional general. El Tribunal de Justicia parece inclinarse por esta opción, desde un primer momento, si traemos a colación su pronunciamiento de 12 de diciembre de 1972 en el que señaló que: "(1)a incompatibilidad de un acto comunitario con una disposición de derecho internacional puede afectar la validez de este acto si la Comunidad está en principio ligada por tal disposición (y) (q)ue, en el caso en el que la invalidez es invocada ante una jurisdicción nacional, es necesario además que esta disposición permita atribuir a los justiciables de la Comunidad el derecho a acudir a la justicia". ${ }^{27}$

Aunque está mención la hizo refiriéndose a un tratado internacional, si se sigue sosteniendo que el derecho internacional general también vincula a la UE, podemos llegar a la conclusión de que puede acudirse a la justicia comunitaria exigiendo la conformidad de un acto normativo con la costumbre o los principios generales del derecho internacional. Esta interpretación también ha sido realizada por la Abogacía General del Tribunal de Justicia que admitió en el asunto referido de 16 de junio de 1998 que: "los particulares pueden impugnar actos comunitarios basándose en normas de derecho consuetudinario internacional, pero que esa impugnación sólo prosperará si existe una infracción manifiesta de tales normas que perjudique al particular de que se trate". ${ }^{28}$

Precisamente, el Tribunal de Justicia, confirmó en este mismo caso de 16 de junio de 1998 que: "cuando un justiciable invoca ante los Tribunales derechos que él basa directamente en un Acuerdo con un país tercero, no puede negársele la facultad de impugnar la validez de un Reglamento... e invocar, para impugnar su validez, las obligaciones derivadas de las normas del derecho consuetudinario internacional". ${ }^{29}$

Por consiguiente, la costumbre y los principios generales del derecho internacional forman parte del ordenamiento jurídico comunitario, con un rango que se sitúa en la práctica por debajo de los tratados constitutivos de la UE y en pie de igualdad con los tratados internacionales celebrados por las instituciones comunitarias con terceros. Esta posición privilegiada permite que el derecho internacional general pueda ser invocado para invalidar cualquiera de los actos normativos adoptados por las

27 TJ. Sentencia "International Fruit Company NV y otros" de 12 de diciembre de 1972. Ibidem, párrs. 7 y 8.

28 TJ. Conclusiones del abogado general F. G. Jacobs de 4 de diciembre de 1997, Rec. 1997, p. I-3679, párr. 76.

29 TJ. Sentencia “Racke GMBH \&Co. y Hauptzollamt Mainz”. Ibidem, párr. 51. 
instituciones comunitarias, lo que convierte a la costumbre y los principios generales del derecho internacional en un límite normativo a las actuaciones de la organización europea.

\section{La verificación práctica}

Aunque el Tribunal de Justicia reconoció que no existía una competencia explícita o implícita en materia de derechos humanos, ${ }^{30}$ este órgano judicial se encontró en la tesitura de salvaguardar los derechos humanos cada vez que le presentaban una cuestión o litigio en el que tales derechos fundamentales pudieran ser conculcados. ${ }^{31}$ Ante la falta de una base jurídica que le permitiese considerarlos, el Tribunal de Justicia apeló a fuentes materiales externas provenientes del ordenamiento jurídico internacional y de los ordenamientos jurídicos internos de los Estados miembros. Dentro de las primeras, hace uso del derecho internacional general (costumbre y principios generales del derecho internacional) así como del derecho internacional particular (tratados internacionales), entre los que se encuentra el Convenio Europeo de Derechos Humanos que constituye una fuente de inspiración "particular". ${ }^{32}$ Esto quiere decir que la costumbre y los principios generales del derecho internacional sólo son una parte de las fuentes materiales externas que el Tribunal de Justicia utiliza en su misión de identificar y garantizar un catálogo de derechos básicos inexistente en los tratados comunitarios. ${ }^{33}$

Cualquiera que sea la fuente de inspiración que permite al Tribunal de Justicia identificar los derechos humanos que se ha comprometido a garantizar, puede afirmarse que, de un lado, la costumbre y los principios generales del derecho evocan derechos fundamentales que necesariamente han de ser observados; y de otro lado, el respeto de tales derechos fundamentales constituye una condición sine qua non para que los actos ju-

30 TJ. Dictamen 2/94 de 28 de marzo de 1996, Rec. 1996, párrs. 26 y 27.

31 TJ. Sentencia "Erich Stauder c. Ville d'Ulm" de 12 de noviembre de 1969, as. 29/69, Rec. 1969.

32 Sánchez Patrón, J. M., "El Convenio Europeo de Derechos Humanos en la jurisprudencia del Tribunal de Justicia de las Comunidades Europeas", Revista General de Derecho, mayo de 2001, núm. 680, pp. 3387-3410.

33 Pese a las dificultades de sistematización, el Tribunal de Justicia hace uso indistinto de los principios generales de derecho, los principios generales propios del ordenamiento comunitario, principios generales de derecho internacional público y, por último, los principios comunes a los sistemas jurídicos de los Estados miembros. Campins Eritja, M., Proceso de integración en la Unión Europea, Barcelona, Bosch, 1996, p. 89. 
rídicos comunitarios puedan considerarse válidos. En efecto, el Tribunal de Justicia ha señalado que: "el respeto de los derechos humanos constituye, por consiguiente, un requisito para la legalidad de los actos comunitarios". 34

Por este motivo, los derechos fundamentales contemplados en normas de derecho internacional general son una limitación a la actuación de las instituciones comunitarias hasta el punto de que un acto jurídico puede ser considerado como inválido por no respetar los derechos humanos identificados por el Tribunal de Justicia.

Así, la sociedad Opel Austria denunció la adopción de un reglamento comunitario por las instituciones comunitarias pese a que éstas conocían con certeza la fecha en la que entraría en vigor un acuerdo internacional que contradecía las disposiciones recogidas en el reglamento comunitario referido. Por este motivo, la sociedad austriaca consideró que la adopción consciente de este reglamento comunitario vulneraba su derecho a la protección de la confianza legítima así como su derecho a la seguridad jurídica. Para el Tribunal de Justicia ambos derechos constituyen dos principios que junto con el de buena fe - con el que se encuentra estrechamente ligado - forman parte del "derecho internacional consuetudinario". ${ }^{35}$ Pues bien, los hechos del caso demostraron que los principios de confianza legítima y de seguridad jurídica fueron conculcados, de tal manera que: "debe considerarse que estas dos violaciones de principios generales del derecho son por sí mismas lo suficientemente graves como para causar la anulación del Reglamento impugnado (el subrayado es nuestro)". ${ }^{36}$

De este modo el Tribunal de Justicia anuló el reglamento comunitario impugnado por no haber respetado derechos básicos de la sociedad litigante, los cuales formaban parte del derecho internacional general.

Por el contrario, una nacional búlgara invocó ante el Tribunal de Justicia un acuerdo de asociación suscrito entre las Comunidades Europeas y sus Estados miembros y la República de Bulgaria, en virtud del cual le confería el derecho a establecerse y a residir en los países miembros de la Unión para el ejercicio de actividades profesionales. El ejercicio de este derecho se encontraba supeditado a la normativa de inmigración del país

34 TJ. Dictamen 2/94 de 28 de marzo de 1996. Rec. 1996, párr. 34.

35 TPI. Sentencia "Opel Austria GmbH contra Consejo de la Unión Europea" de 22 de enero de 1997, as T-115/94, Rec. 1997, párrs. 90-93

36 Ibidem, párr. 126. 
de destino, a lo que se sumó la exigencia de que solicitase formalmente el derecho a establecerse en el Estado miembro elegido. Para la nacional búlgara, esta solicitud de establecimiento para el ejercicio de actividades profesionales no era exigida a los propios nacionales del país destinatario de la solicitud, razón por la cual consideraba que se le conculcaba su derecho a recibir un trato no discriminatorio. El Tribunal de Justicia declaró que, según su jurisprudencia:

La libre circulación de trabajadores... permite a los Estados miembros adoptar, respecto a nacionales de otros Estados miembros... en particular por razones de orden público, medidas que no podrían aplicar a sus propios nacionales... Esta diferencia de trato entre los propios nacionales y los de los demás Estados miembros deriva de un principio de derecho internacional que se opone a que un Estado miembro niegue a sus propios nacionales el derecho a entrar en su territorio y a permanecer en él, principio respecto al cual no cabe suponer que el Tratado no lo haya tenido en cuenta en las relaciones entre Estados miembros. ${ }^{37}$

Los derechos humanos identificados en la jurisprudencia comunitaria son concebidos para que puedan aplicarse a una realidad específica en la que deben tenerse en cuenta las exigencias propias de la construcción comunitaria. ${ }^{38}$ Este condicionante y la falta de un catálogo escrito de derechos fundamentales permiten que el Tribunal de Justicia goce de un importante margen de discrecionalidad a la hora de interpretar y aplicar a los casos concretos los derechos humanos deducidos de la costumbre y los principios generales del derecho internacional. Sin embargo, el nuevo Tratado por el que se establece una Constitución para Europa incorpora un catálogo escrito de derechos fundamentales que vinculará a las instituciones comunitarias y que evitará que su órgano judicial tenga que acudir a fuentes materiales externas para identificar cuales son los derechos humanos que deben ser respetados. ${ }^{39}$ No obstante y pese a esta limitación del margen de discrecionalidad judicial, la propia Carta de derechos fundamentales de la Unión Europea establece que: "(n)inguna de las disposiciones de la presente Carta podrá interpretarse como limitativa o lesiva

37 TJ. Sentencia "Eleanora Ivanova Kondova" de 27 de septiembre de 2001, as. C-235/99, Rec. 2001, párrs. 83 y 84. Las cursivas son mías.

38 TJ. Sentencia "Wachauf c. Bundesamt für Ernährung und Forstwirtschaft" de 13 de Julio de 1989 , as. $5 / 88$, Rec. 1989 , párr. 18.

39 Artículos II-61 a II-114. 
de los derechos humanos y libertades fundamentales reconocidos, en su respectivo ámbito de aplicación, por... el derecho internacional' ${ }^{40}$

Sin embargo, la necesidad de respetar ciertos derechos fundamentales no es la única exigencia derivada del derecho internacional general que ha sido invocada ante el Tribunal de Justicia. El examen de su jurisprudencia nos permite comprobar que la jurisdicción comunitaria ha conocido asuntos en los que han sido alegados la conculcación de obligaciones internacionales en materia de territorialidad estatal, así como en materia de sucesión de Estados.

Por lo que respecta a la primera de las cuestiones, varias empresas extranjeras concertaron el precio de venta de la pasta de madera que se importaba en los países miembros. A juicio de la comisión, esta medida era contraria a la libre competencia prevista en las disposiciones del Tratado Constitutivo de la Comunidad Económica Europea, razón por la cual fueron sancionadas en virtud de una decisión adoptada el 19 de diciembre de 1984. Las empresas interesadas solicitaron la anulación de esta decisión ante el Tribunal de Justicia debido a que la medida adoptada tenía una aplicación extraterritorial - las empresas eran extranjeraslo que implicaba un menoscabo del principio de territorialidad así como del de no intervención previstos por el derecho internacional general. Según el Tribunal de Justicia, la concertación del precio por parte de las empresas extranjeras repercutía en el seno de la Comunidad Económica Europea, razón por la cual no existía una vulneración del principio de territorialidad. Asimismo, y en relación con el principio de no intervención, el Tribunal de Justicia señala que:

(P)or lo que respecta a la violación del principio de no intervención, conviene precisar que los demandantes... se refieren a una regla según la cual, cuando dos Estados tienen competencia para promulgar y para ejecutar dichas normas y éstas consiguen que una persona se encuentre obligada por dos órdenes contradictorios en cuanto al comportamiento que deben seguir, cada Estado deberá ejercer su competencia con moderación. Los demandantes han concluido que aplicando su derecho a la competencia desconociendo esta regla, la Comunidad ha vulnerado el principio de no intervención. Sin que sea necesario indagar sobre la existencia en derecho internacional de la regla tal y como se invoca, resulta suficiente constatar que las condiciones de aplicación no son, en cualquier caso, cumpli- 
das. En efecto, no hay, en el presente caso, contradicción entre el comportamiento prescrito por los Estados Unidos y el prescrito por la Comunidad... Por otra parte, conviene señalar que las autoridades de los Estados Unidos no han planteado objeciones derivadas de un eventual conflicto de competencias, cuando ellas han sido consultadas por la comisión, conforme... a la cooperación de los Estados miembros en casos de prácticas comerciales restrictivas que afectan a los intercambios internacionales. ${ }^{41}$

Por todo ello, el Tribunal de Justicia llega al convencimiento de que el principio de no intervención, previsto por el derecho internacional general, no ha sido conculcado en este asunto. ${ }^{42}$

A la misma conclusión anterior llegó la jurisdicción europea tras examinar un caso en el que fue cuestionado el derecho internacional general en materia de sucesión de Estados. A raíz de la declaración de independencia de la Antigua República Yugoslava de Macedonia, un tribunal belga planteó una cuestión prejudicial al Tribunal de Justicia en el que le interpelaba acerca de la aplicación de una decisión de la comisión relativa al establecimiento de derechos antidumping sobre las importaciones de determinadas chapas de hierro o acero "originarias de Yugoslavia". Tras el desmembramiento de la antigua República Federativa Socialista de Yugoslavia, sólo una de ellas: la República Federativa de Yugoslavia, se convirtió en su sucesora. El resto de las entidades políticas desmembradas se convirtieron posteriormente en nuevos Estados independientes. La Antigua República Yugoslava de Macedonia fue uno de ellos, reconocido en 1991. Un año después, uno de los importadores de material a los que se refiere la decisión de la comisión citada, operaba desde su capital, Skopje. La cuestión que se plantea, entonces, consiste en averiguar si la aplicación de dicha decisión de la comisión se extiende a la independizada Antigua República Yugoslava de Macedonia o no. A favor de una respuesta negativa concurren dos argumentos: el primero apunta a la existencia de un nuevo Estado independiente y, el segundo, que sugiere que la reciente República Federativa de Yugoslavia, como sucesora, es la única que puede asumir los compromisos asumidos por la antigua

41 T J. Sentencia “A. Ahlström Osakeyhtiö y otros c. Comunidades Europeas" de 27 de septiembre de 1988, as. 89, 104, 114, 116, 117 y 125 a 129/85, Rec. 1997, párrs. 19-21.

42 En este mismo sentido, véase T J. Sentencia "Gencor Ltd c Comisión" de 25 de marzo de 1999, as. T-102/96, Rec. 1999, párrs. 103-108 
República Federativa Socialista de Yugoslavia de conformidad con el derecho internacional general relativo a la sucesión de Estados.

Con respecto al primero de los argumentos, el Tribunal de Justicia ha contestado que: "las medidas antidumping controvertidas tienen por objeto proteger la producción comunitaria frente a productos importados de países terceros en la Comunidad a un precio inferior a su valor normal que, en consecuencia, pueden causar un perjuicio a los productores comunitarios". 43

Pues bien, "una modificación en la denominación o en la organización política del territorio geográfico que se indica como país de origen o de exportación en una Decisión que establece derechos antidumping provisionales o definitivos no tiene ninguna incidencia en el objetivo económico del derecho antidumping establecido y, por consiguiente, no puede por sí mismo hacer inaplicable este derecho a los productos procedentes de dicho territorio". ${ }^{44}$

Además:

El hecho de que, en derecho internacional público, dicho proveedor esté sujeto a la competencia de un nuevo Estado no impide que sus prácticas de dumping continúen perjudicando a una producción comunitaria [el subrayado es nuestro]. En el caso... (se) establece un derecho antidumping definitivo sobre las importaciones de determinados productos siderúrgicos originarios de Yugoslavia, estaba destinada en la época de su adopción a ser aplicada a todo el territorio de la República Federativa Socialista de Yugoslavia. Si mientras tanto dichas República se dividió en varios Estados, al expresión "Yugoslavia" empleada en la Decisión... sólo puede designar la misma zona geográfica que antiguamente era el territorio de dicha República y ahora corresponde al conjunto de los territorios de dichos Estados, incluido el de la Antigua República Yugoslava de Macedonia. ${ }^{45}$

Por último, el segundo de los argumentos alegados es también rechazado por el Tribunal de Justicia, ya que entiende que el derecho internacional general relativo a la sucesión de Estados no es aplicable a este

43 T J. Sentencia "Belsische Staat c. Banque Indosuez y otros y Comunidad Europea" de 16 de octubre de 1997, as. C-177/96, párr. 19.

44 Ibidem, párr. 21.

45 Ibidem, párr. 22. 
caso, por el simple hecho de que los derechos antidumping: "no constituyen deudas de Estado, sino derechos adeudados por los particulares". ${ }^{46}$

Con los razonamientos reproducidos, el Tribunal de Justicia confirma la aplicación de la decisión comunitaria controvertida sin que considere que los principios generales del derecho internacional invocados puedan limitar el sentido de su pronunciamiento. No debe olvidarse que la decisión de la comisión objeto de la cuestión prejudicial estaba basada en el articulado del Acuerdo General sobre Aranceles Aduaneros y Comercio, del que la República Federativa Socialista de Yugoslavia formaba parte, pero de la que no lo era la actual Antigua República Yugoslava de Macedonia. Esta circunstancia debería haber llevado al Tribunal de Justicia a examinar si era aplicable la presunción de continuidad de los tratados internacionales con vistas a resolver correctamente la problemática planteada. ${ }^{47}$

\section{CONCLUSIONES}

Aunque la costumbre y los principios generales del derecho internacional no constituyan fuentes expresas del derecho de las organizaciones internacionales, lo cierto es que la práctica demuestra que estos sujetos internacionales no sólo contribuyen a la formación y aplicación del derecho internacional general sino que también utilizan éste ordenamiento jurídico para fundamentar o limitar sus actuaciones. Así se explica que, sin ir más lejos, el Consejo de Seguridad de las Naciones Unidas instituyese dos tribunales internacionales ad hoc para enjuiciar y castigar los crímenes internacionales cometidos en la ex Yugoslavia y Ruanda, mientras que también estableció cual era la normativa jurídica aplicable por estas jurisdicciones, basándose para ello en el derecho internacional general. ${ }^{48}$ Por otra parte, el mismo Consejo de Seguridad instó a que se respeten las reglas jurídicas previstas en los Convenios de Ginebra de de 12 de agosto de 1949, sin que las propias Naciones Unidas sean parte en estos tratados

46 Ibidem, párr. 25.

47 Ibidem, párr. 5. Al respecto, véase Dumberry, P., Turp, D., "La sucessión d'États en matière de traités et le cas de la sécession: du principe de la table rase à l'èmergence d'une présomption de contitunité des traités", Revue Belge de Droit international, núm. 2, 2003, especialmente pp. 391-398.

$48 \mathrm{~S} / \mathrm{RES} / 827(1993)$ de 25 de mayo de 1993, párr. 1o. y S/RES/955 (1994) de 8 de noviembre de 1994, párr. 10. 
internacionales, lo que resulta jurídicamente factible desde el momento en que la organización internacional considera que dichas reglas jurídicas le vinculan en virtud de su naturaleza consuetudinaria. ${ }^{49}$

Así pues, que las organizaciones internacionales se encuentran sometidas a la costumbre y a los principios generales del derecho internacional no constituye ya una posición jurisprudencial o una construcción doctrinal, sino que la propia práctica de las organizaciones internacionales permiten constatar esta afirmación. El presente estudio se ha centrado en el análisis de una organización regional, la UE, que se caracteriza por su dimensión integradora, y por consiguiente por la especificidad con la que le han sido atribuidas sus competencias institucionales por parte de los Estados miembros, así como por la determinación con la que éstas han sido ejercidas. Pese a esta singularidad, el análisis de la jurisprudencia de su órgano judicial nos ha permitido comprobar que el recurso al derecho internacional general es, cada vez, más frecuente, no sólo para fundamentar las actuaciones de las instituciones comunitarias sino para poner límites a las mismas.

La utilización de la costumbre y los principios generales del derecho internacional permite que las instituciones comunitarias fundamenten sus actuaciones institucionales colmando la falta de base jurídica o completando ésta, de tal manera que puede advertirse que el derecho internacional general puede servir de soporte jurídico a una actuación comunitaria de la que es materialmente competente, pero de la que carece de alguna base jurídica, o bien necesita que ésta pueda ser completada. Asimismo, la costumbre y los principios generales del derecho internacional constituyen un límite a las actuaciones comunitarias, hasta el punto de que éstos lleguen a ser utilizados como un condicionante en el ejercicio de sus

49 Así, por ejemplo, el Consejo de Seguridad actuando en virtud del capítulo VII de la Carta ONU y en relación con la situación de Irak “(i)nst(ó) a quienes conc(erniese) cumplir cabalmente las obligaciones que les incumben en virtud del derecho internacional, en particular los Convenios de Ginebra de 1949 y el Reglamento de la Haya de 1907”. S/RES/1483 (2003) de 22 de mayo de 2003, párr. 5o. 
competencias institucionales, o incluso, sirvan de justificación a la declaración de invalidez de una norma o acto comunitario contrario al derecho internacional general. ${ }^{50}$

50 Pese a la posibilidad apuntada, pueden advertirse ciertas reticencias a que se produzca este efecto invalidatorio. Ott, A., "Thirty years of case-law by European Court of Justice on International law: a pragmatic approach towards its integration", Kronenberger, V. (ed.), The European Union and the International legal order: discord or harmony?, The Hague, TMC Asser Press, 2001, pp. 133-136; Vkuijper, P. J., "From Dyestufffs to Kosovo wine. From avoidance to acceptance by The European Community Courts of customary international law as limit to community action", en Dekker, I. F y Post, H. G. (ed.), On the Foundations and Sources of International Law, The Hague, TMC Asser Press, 2003, p. 170. 